\title{
ROLE OF HURST EXPONENT IN PREDICTION OF MARKET EFFICIENCY IN KSE-100 INDEX
}

\author{
Syeda Tayyaba Ijaz ${ }^{1}$ \\ Department of Business Administration, International Islamic University \\ Islamabad \\ Rabia Komal ${ }^{2}$ \\ Pakistan Institute of Development Economics (PIDE), Islamabad
}

\begin{abstract}
Purpose:- This paper aims to investigate the Efficient Market Hypothesis (EMH) and validity of Random Walk Model (RWM) in KSE-100 index starting from 1992 till 2014 taking monthly averages of index.

Methodology:- Main focus of the paper is to evaluate the efficiency in KSE-100 index with respect to application of Hurst Exponent and Rescaled Ranged Statistics. Although many researchers have previously explained the working of EMH in KSE-100 index but rarely anyone has explained it using Hurst Exponent Analysis on over all longest period since the establishment of KSE-100 index Feb, 1992 to Dec, 2014. Annual Rescaled Range Statistics are also calculated to explain the good or bad years according to Estimated Hurst Statistics. All statistical analysis has been performed on Gretl which gives the good grasp over Hurst Exponent Analysis.
\end{abstract}

Results:- The results revealed that overall KSE-100 index is not following the random walk and is not performing efficiently, and yearly break up shows that market was persistent in few years but mostly it was antipersistent (long-run memory prevails).

Practical Implication:- Implementing Hurst Exponent Analysis enabled us to get rigorous result about performance of the Pakistan stock market in terms of efficiency that implied chances of arbitrage opportunity prevail significantly.

Keywords : Efficient Market hypothesis, Random Walk, KSE-100 index, Hurst Exponent Analysis, De-trended Functional Analysis

Jel Classification: D920, E220, F210

\footnotetext{
* The material presented by the author does not necessarily portray the viewpoint of the editors and the management of the Institute of Business \& Technology (IBT)

* Syeda Tayyaba Ijaz

: syedatayyaba110@gmail.com

* Rabia Komal :rabia_komal_09@yahoo.com

(C) IBTJBS is published by the Institute of Business and Technology (IBT).

Main Ibrahim Hydri Road, Korangi Creek, Karachi-75190, Pakistan.
} 


\section{INTRODUCTION}

In understanding the behavior of different security markets, efficiency analysis plays a major role. Efficiency means all available information about security is reflected into its price, so it's obvious that no one can beat the market by predicating the future prices. Theory that introduced and elaborated this concept of efficiency is known as Efficient Market Hypothesis presented by Fama. EMH endorse that security prices are always at their fair value in the market, hence there is no chance to buy undervalued security and sell overvalued security to outperform the market. In short, trend analysis is of no use. Security prices will always be showing a random walk. It is important to note that "Efficient market hypothesis" does not discourage the investment rather it suggests that the returns should be according to the fair value of the securities and corresponding risk of the securities, thus it protects the right of investors. To get the grasp about the working of any stock exchange, it's significant to test the efficiency of market to know the future prospect of investment in those exchanges or Forex markets. Hurst Exponent is procedure of analyzing the presence of efficiency in the market. It shows the relationship between long run time series data. Current study will elaborate the market efficiency concept in Karachi Stock Exchange (KSE-100) Index by implementing Hurst exponent model in Pakistan. Thus, present study fills the gap in existing literature by implementing Hurst Exponent Analysis to test efficiency of Pakistan stock market (KSE) for quite long time period from year 1992 to 2014, getting robust results.

\section{LITERATURE REVIEW}

Being Efficient, concept was explained by Fama (1970). He explained three types of efficiency prevailing in the market; mainly weak form efficient, semi strong form efficient and strong form efficient. With the time, scholars worked on all three types and determined that it may be possible to get weak form efficient, somehow semi strong form of efficiency but there is no test yet to explore for the strong form of efficiency. Regression analysis, time series analysis, vector auto regression and linear co-integration were old ways to test the efficiency. Makovský (2014) conducted a study on exchanges in EU countries and concluded that researches should choose up to date models for predicting efficiency because it could affect the rules and regulation governing the trade. Study claims that there is strong tendency of nominal convergence in EU countries. Lee, Lee and Lee (2010) elaborated the concept further that real stock prices indices are stationary process and that contradicts with EMH. Their results suggest that arbitrage opportunity prevails. McCauley, Bassler and Gunaratne (2008) discussed that in order to understand efficiency researchers should expand their view incorporating nonstationary increments and martingales. Study criticized the finding of Fama (1970) that there is no "fair game" in market; serial data set has the nature of memory to exploit. Lee and Lee (2009) explained energy sector prices, and results proved that broken stationary hypothesis is present and EMH is not acting well in energy sector; plus study explains whenever any breakout is witnessed, it is linked with critical events in determination of oil, coal, gas and electricity prices.

McCauley, Bassler and Gunaratne (2008) added in research that Markovian markets 
have no memory to exploit. Timmermann and Granger (2004) proposed that forecasters constantly look for any mispricing in the market, forecasting patterns are not stable for long period of time and will immediately disappear when majority of investor invest in that direction. Chen and Yeh (2002) assumed that study of EMH and rational expectation hypothesis can be used to shed the light on difference of macro behavior and micro behavior of investors; genetic programming proves that both behaviors cannot be generalized. Urquhart and McGroarty (2014) extended the dimension of EMH by incorporating Adoptive Market Hypothesis using calendar anomaly; result were in favor of $\mathrm{AMH}$, hence ranking $\mathrm{AMH}$ high than $\mathrm{EMH}$.

Ghazani and Araghi (2014) also used AMH and finding suggests that after repetitive test, result confirms the effectiveness of AMH. Majumder (2013) developed a model for stock and bond pricing that can be very useful for less than efficient market because previous model assumes that market is efficient and many empirical studies shown that markets are not efficient; so proposed model will sort out the dilemma of pricing model. Chen and Yeh (2001) suggested that inclusion of genetic programming based model is better measure of prediction of efficiency than random walk. Study reveals that even for the very short time span, prices are irregular, it would be very expensive to search them out so study endorse EMH. Urquhart and Hudson (2013) proved that linear dependence of stock returns varies but nonlinear dependencies strong throughout. Overall results support AMH and contradict with EMH. Manahov and Hudson (2014) have found that heterogeneity and genetic diversity lead towards high market efficiency; plus results show that markets dynamics and nonlinearity is better encountered by $\mathrm{AMH}$ because traders adopt with the time. Homma, Tsutsui and Uchida (2014) proposed a new test of market efficiency known as Efficient Structure (ES) hypothesis whose findings show that firms which are more efficient tend to grow more than others. Jamaani and Roca (2015) concluded that both individually and collectively, gulf stock markets are not efficient and they claimed it to be the result of less foreign participation and great degree of predictability in Gulf markets. Kan and O'Callaghan (2007) conducted a study on foreign exchange market efficiency on Asian (Korea, Taiwan, Thailand, Indonesia, Malaysia, Philippines, Japan, Singapore) and Australasian (Australia, New Zealand) markets and generated results supporting the EMH.

Mockus and Raudys (2010) explained that adding new dimension of Nash Equilibrium in testing market efficiency for financial stocks whose values are derived from anticipation based on N major investors, finding of study confirms with EMH. Drakos (2003) tested multi maturity efficient market hypothesis; results show that multimarket efficiency market hold in forward exchange market but on the assumption of matching rates. Manahov, Hudson and Hoque (2015) used Strongly Typed Genetic Programming (STGP)-based trading for predicting one day ahead results, those were compared with benchmark predictions and STGP out performed them.

Goldman (2000) conducted a study on gold rates and results show EMH hold true if truncation points are added. Gozbasi, Kucukkaplan and Nazlioglu (2014) studied the Borsa Istanbul stock price index series and results show that prices have nonlinear 
behavior and random walk is present, supporting EMH. Kim and Shamsuddin (2008) found that Hong Kong, Japanese, Korean and Taiwanese markets are weak form efficient; Indonesia, Malaysia and Philippines are not efficient and Singaporean and Thai markets become efficient after Asian Crisis. Charles, Darné and Kim (2015) studied that return forecasts in precious metal markets is evolving with time. Political conditions and economic condition have impact on returns, plus weak form efficiency is gradually increasing in these markets. Akhigbe and Whyte (2015) elaborated the impact of seasoned equity offerings (SEOs) \& internal capital markets mitigate the negative announcement returns. Both have positive relation, so through this procedure favorable return could be drawn for high efficiency firm. Majumder (2014) stressed on the need of less strict asset pricing model with respect to efficiency. Aumeboonsuke and Dryver (2014) used different models for answering the questions about efficiency of financial markets, plus they discussed issues relating to different model and data employed. Abounoori, Shahrazi and Rasekhi (2012) introduced the de-trended fluctuation analysis (DFA) technique to study the market efficiency. Their finding suggest that Iranian Forex market is not weak form efficient but degree of inefficiency vary over time, arbitrage opportunities are available in the market. Rodriguez, Cornejo, Femat and Ramirez (2014) incorporated the concept of AMH to test that characteristics of EMH prevails in Dow Jones Index Average (DJIA). Results shown that efficiency vary from time to time and in long run from week, months and years. Hunter and Coggin (1988) used new dimension of psychological process in predicting the trading patterns. Results reveal that EMH doesn't hold true and process does play its role.

Goodhart (1986) conducted a study on Wall Street and London stock exchange because of ambiguous time difference results. Bianchi and Jehiel (2015) studied the extent from which security prices differs from the fundamental prices; they assumed that monopolistic can change the prices from fundamental, and competition also plays major role.

Katusiime, Shamsuddin and Agbola (2015) claimed on the basis of their study that Ugandan foreign exchange market suffering from inefficient prices, but for very less time in history, short term efficiency is reported; plus because of transaction cost and time variation traders are not able to beat the market again and again. Eom, Choi, Oh and Jung (2008) employed Hurst exponent and hit rate in analysis of efficiency whose empirical results showed strong positive relation between Hurst exponent and hit rate.

Hull and McGroarty (2014) studied the relation between financial market efficiency and economic development, results shown efficiency in returns and volatility for 'advanced' emerging markets. Ramirez, Rodriguez and Paredes (2012) tested market efficiency in terms of entropy concepts and show that US market efficiency has suffered a slight decline from last decade. Szafarz (2012) proposed a model where speculator and fundamentalist can co-trade and excessive volatility created by speculator would be financed by fundamentalist. Charles and Darné (2009) shows that in Shanghai and Shenzhen stock market efficiency has been tested for Class A \& B share; and class A shares are more efficient while Class B shares are bit inefficient. D. Uri and D. Jones (1990) paper analyzed the efficiency for financial assets including common stocks, preferred stocks and government bonds. For all three types of financial assets, market is shown to be efficient in US. Tiwari and Kyophilavong (2014) studied the market 
efficiency in BRICS countries and only Russian market has shown some points of efficiency.

Yan-Ki Ho (1985) analyzed the efficiency of London gold market and finding suggests that London gold market is incrementally efficient and there are no traces of predictability. Rizvi, Dewandaru, I. Bacha and Masih (2014) have shown comparative analysis of exchanges in Islamic countries and developed countries whose result showed that exchanges in Islamic countries are more efficient particularly in period of crisis. Mobarek and Fiorante (2014) have shown the prospects of BRIC countries equity markets efficiency, their results claim them heading towards weak form efficient. Verheyden, Moor and Bossche (2015) conducted research to test the EMH and AMH, result shown that market has the nature of being adoptive and evolving over time hence AMH is preferred.

\section{METHODOLOGY}

In this study, KSE-100 Index will be used as benchmark for evaluation of market efficiency in Pakistan. Data period considered in research is from 1992 to 2014. Gretl software is used for analysis purpose. Daily traded value of index is used after calculating the return; logarithm return change would be matter of interest and for whole series natural logarithm will be computed as follows:

\begin{tabular}{|c|c|}
\hline 1 & $\ln =\mathrm{pt}$ \\
\hline 2 & $\ln =\mathrm{pt}-1$ \\
\hline$n$ & $\ln =\mathrm{pt}-(\mathrm{n}-1)$ \\
\hline
\end{tabular}

Previous studies have employed the methods of unit root test, regression, correlation. Few studies have used Hurst exponent. After computing the log returns, Hurst exponent test will be used to assess the level of efficiency in KSE-100 index. For quantifying the degree of long term memory characteristic of data series, De-trended Fluctuation Analysis (DFA) method is best way to accurately calculate Hurst exponent.

First of all, mean of data series will be calculated and after that, all data sets will be excluded from that mean, so we will get the new series as $\left(\mathrm{y}_{\mathrm{i}}\right)$.

$$
y_{i=\sum_{i=1}^{N}\left(x_{i}-\bar{x}\right)}
$$

Here $\mathrm{N}$ is the number of series. In second step, time series will be divided into window of same length that is $n$, trend line will be estimated that is $\mathrm{y}_{\mathrm{n}}(\mathrm{i})$ by Ordinary least square method. Existing trends will be subtracted from the time series, same model will be implanted on every fluctuation magnitude symbolized as $\mathrm{F}(\mathrm{n})$ : 


$$
F(n)=\sqrt{\frac{1}{N}} \sum_{i=1}^{N}\left[y(i)-y_{n(i)}\right]^{2}
$$

Scaling relationship for whole series will be assessed using following function in which $\mathrm{c}$ is a constant and $\mathrm{H}$ denotes the Hurst exponent:

$$
F(n) \approx c \cdot n^{H}
$$

"If $0=\mathrm{H}<0.5$, then the time series will tend to have a short-term memory (antipersistent) market is efficient and if $0.5<\mathrm{H}=1.0$, it will have a long-term memory (persistent) and market is not efficient".

\section{RESULTS \& DISCUSSION}

Gretl software is used for Hurst Exponent Analysis. Table 1 represents the generated results. Estimated Hurst Exponent is 0.585935. As we have discussed earlier, if estimated Hurst value is between 0 and 0.5 , data series is anti-persistent means no long run memory exists in the series and if value is in the range of 0.5 to 1 , it's obvious that data series is persistent and has the traces of long run memory, which subsequently refers to the efficiency outbreaks in the market that can be exploited by using trend analysis and smart traders will be able to outperform the market.

Figure 1 shows the rescaled range plots for return in Hurst Model which depicts upward slopping.

Figure 2 shows the overall movement of returns along the time horizons. It's eventually evident that average index returns has been decreased over the time and market is showing less volatility, as the range of candles and up lows in same period is getting narrow over the time. 
For confirmation of Hurst's results, we have also employed unit root test to check the level of stationarity in the data series. For this purpose, KPSS test is chosen to be best fit on data as it clearly states the null hypothesis (data is stationary). KPSS is employed for both level and $1^{\text {st }}$ difference. Null hypothesis can be rejected for level and can't be rejected for $1^{\text {st }}$ difference. According to KPSS test, data series is stationary at $1^{\text {st }}$ difference, now Random Walk Model is non-stationary model. In order to perform the financial analysis, data series has to be stationarity.

Table 4 represents the Hurst exponents calculated separately for each year using monthly index value for respective year, although overall Hurst Exponent reveals that KSE-100 index is not an efficient market but we dragged it bit further to clarify the years in which market was troubling more to efficiency and jumbling more to outperformers. De-trended Functional Analysis result for each year are reported since the establishment of KSE-100 index and respective outcome of being persistent or ant persistent is also reported in the table.

Figure 3 shows the trend of yearly Hurst along the years, v1 represents the years starting from 1992 to the end of 2014 and v2 depicts the Annual Hurst Exponent.

\section{CONCLUDING REMARKS}

After conducing thorough analysis of implication of Hurst Exponent on KSE-100 index in both ways-overall and yearly break up, it's apparent that KSE-100 index is not showing efficient behavior. Purpose of the paper is not to thoroughly describe the reasons for not being efficient, rather we are interested to explain that stock market of any economy is considered to be the benchmark for the performance of that economy, while using traditional OLS regression model and regressing the variable with any other micro or macroeconomic variable we can have glittery results as many researchers have reported. Very few studies have implied Husrt Exponent to thoroughly explain the working of stock exchanges. One thing more to worry is decreasing returns over the years as rupee is getting depreciated so trend is getting more downward. Now we leave the explanation of efficient years and non-efficient years for some other time or for some other researchers; reason could be political or economic or initiating Chaebols 
system of Pakistan.

\section{ACKNOWLEDGEMENT}

First of all with a profound gratitude, we are thankful to Almighty Allah forgiving us success, knowledge and understanding without which we would not been capable of completing this research paper.

We are also profoundly grateful to all our family members whose endurance and understanding have played a significant role in our success by sacrificing the important family time and supporting us all over the research work.

We are finally thankful to the editor, reviewers and IBT specially who provided us with the opportunity to publish our research paper in this esteemed journal.

\section{REFERENCES}

Abounoori, E., Shahrazi, M., \&Rasekhi, S. (2012). An investigation of Forex market efficiency based on detrended fluctuation analysis: A case study for Iran.ÊPhysica

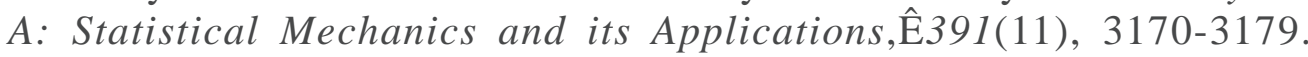
Akhigbe, A., \& Whyte, A. M. (2015). SEO announcement returns and internal capital market efficiency. $\hat{E} J o u r n a l ~ o f ~ C o r p o r a t e ~ F i n a n c e, \hat{E} 31,271-283$. Alvarez-Ramirez, J., Rodriguez, E., \& Espinosa-Paredes, G. (2012). Is the US stock market becoming weakly efficient over time? Evidence from 80-year-long data.ÊPhysica A: Statistical Mechanics and its Applications, $\hat{E} 391(22), 5643-$ 5647.

Aumeboonsuke, V., \&Dryver, A. L. (2014). The importance of using a test of weakform market efficiency that does not require investigating the data first.International Review of Economics \& Finance, $\hat{\mathrm{E}} 33,350-357$.

Bianchi, M., \&Jehiel, P. (2015). Financial reporting and market efficiency with extrapolative investors.ÊJournal of Economic Theory, $\hat{\mathrm{E}} 157,842-878$.

Brière, M., Chapelle, A., \&Szafarz, A. (2012). No contagion, only globalization and

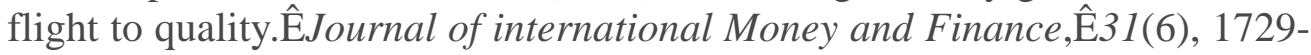
1744 .

Charles, A., \&Darné, O. (2009). Variance-ratio tests of random walk: an overview.ÊJJournal of Economic Surveys, $\hat{\mathrm{E}} 23(3), 503-527$.

Charles, A., Darné, O., \& Kim, J. H. (2015). Will precious metals shine? A market efficiency perspective.ÊInternational Review of Financial Analysis.

Chen, S. H., \&Yeh, C. H. (2001). Evolving traders and the business school with genetic programming: A new architecture of the agent-based artificial stock market.ÊEJournal of Economic Dynamics and Control, $\hat{E} 25(3), 363-393$.

Chen, S. H., \&Yeh, C. H. (2002). On the emergent properties of artificial stock markets: the efficient market hypothesis and the rational expectations hypothesis.ÊJournal of Economic Behavior \& Organization, $\hat{\mathrm{E}} 49(2), 217-239$. 
Drakos, K. (2003). The term structure of deviations from the interest parity.Journal of International Financial Markets, Institutions and Money,ÊE13(1), 57-67.

Eom, C., Choi, S., Oh, G., \& Jung, W. S. (2008). Hurst exponent and prediction based on weak-form efficient market hypothesis of stock markets.ÊPhysica A: Statistical Mechanics and its Applications, $\hat{\mathrm{E}} 387(18), 4630-4636$.

Fama, E. F. (1970). Efficient capital markets: A review of theory and empirical work*.ÊThe journal of Finance, $\hat{\mathrm{E}} 25(2), 383-417$.

Ghazani, M. M., \&Araghi, M. K. (2014). Evaluation of the adaptive market hypothesis as an evolutionary perspective on market efficiency: Evidence from the Tehran stock exchange.ÊResearch in International Business and Finance,32, 50-59.

Goodhart, C. (1986). Financial innovation and monetary control.ÊOxford Review of Economic Policy, 79-102.

Gozbasi, O., Kucukkaplan, I., \&Nazlioglu, S. (2014). Re-examining the Turkish stock market efficiency: Evidence from nonlinear unit root tests.ÊEconomic Modelling,Ê.38, 381-384.

Ho, Y. K. (1985). A test of the incrementally efficient market hypothesis for the London gold market.ÊEconomics Letters, $\hat{\mathrm{E}} 19(1), 67-70$.

Homma, T., Tsutsui, Y., \& Uchida, H. (2014). Firm growth and efficiency in the banking

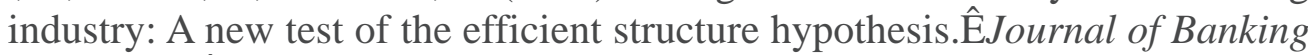
\& Finance, $\hat{\mathrm{E}} 40,143-153$.

Hopper, N., Goldman, C., Gilligan, D., Singer, T. E., \& Birr, D. (2007). A Survey of the US ESCO Industry: Market Growth and Development from 2000 to 2006.Lawrence Berkeley National Laboratory.

Hull, M., \&McGroarty, F. (2014). Do emerging markets become more efficient as they develop? Long memory persistence in equity indices.ÊEEmerging Markets Review, $\hat{\mathrm{E}} 18,45-61$.

Hunter, J. E., Schmidt, F. L., \&Coggin, T. D. (1988). Problems and pitfalls in using capital budgeting and financial accounting techniques in assessing the utility

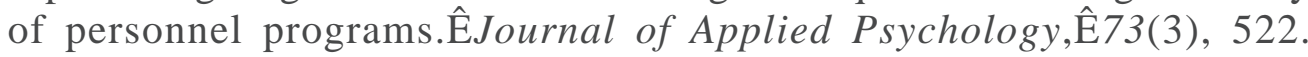

Jamaani, F., \& Roca, E. (2015). Are the regional Gulf stock markets weak-form efficient as single stock markets and as a regional stock market?.ÊResearch in International Business and Finance, $\hat{\mathrm{E}} 33,221-246$.

Jones, J. D., \& Uri, N. D. (1990). Market efficiency, spot metals prices and cointegration: Evidence for the USA, 1964-1987.ÊResources Policy, $\hat{E} 16(4), 261-268$.

Kan, D., \&Andreosso-O'Callaghan, B. (2007). Examination of the efficient market hypothesis - the case of post-crisis Asia Pacific countries.ÊJournal of Asian Economics, $\hat{\mathrm{E}} 18(2), 294-313$.

Katusiime, L., Shamsuddin, A., \&Agbola, F. W. (2015). Macroeconomic and market microstructure modelling of Ugandan exchange rate.ÊEconomic Modelling, $\hat{\mathrm{E}} 45$, 175-186. 
Syeda Tayyaba Ijaz, Rabia Komal

Kim, J. H., \&Shamsuddin, A. (2008). Are Asian stock markets efficient? Evidence from

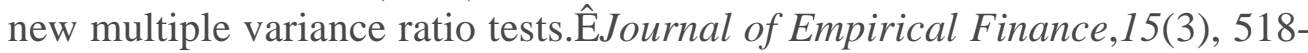
532.

Lee, C. C., \& Lee, J. D. (2009). Energy prices, multiple structural breaks, and efficient market hypothesis. $\hat{E}$ Applied Energy, $\hat{\mathrm{E}} 86(4), 466-479$.

Lee, C. C., Lee, J. D., \& Lee, C. C. (2010). Stock prices and the efficient market hypothesis: Evidence from a panel stationary test with structural breaks. $\hat{E} J a p a n$ and the world economy, $\hat{\mathrm{E}} 22(1), 49-58$.

Lumsdaine, R. L., \&Papell, D. H. (1997). Multiple trend breaks and the unit-root

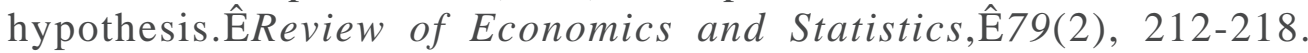

Majumder, D. (2013). Towards an efficient stock market: Empirical evidence from the

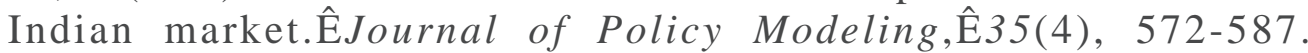

Majumder, D. (2014). Asset pricing for inefficient markets: Evidence from China and India.ÊThe Quarterly Review of Economics and Finance, $\hat{E} 54(2), 282-291$.

Makovský, J., Spurný, P., Mareš, J., Hedbávný, J., \&Vítek, T. (2014). Heavy metal pollution of ecosystem within the middle course of the JihlavaRiver.ActaUniversitatisAgriculturaeetSilviculturaeMendelianaeBrune $n$ sis, $\hat{\mathrm{E}} 58(5), 255-262$.

Manahov, V., Hudson, R., \&Gebka, B. (2014). Does high frequency trading affect technical analysis and market efficiency? And if so, how?.ÊEJournal of International Financial Markets, Institutions and Money, $\hat{\mathrm{E}} 28,131-157$.

Manahov, V., Hudson, R., \&Hoque, H. (2015). Return predictability and the 'wisdom of crowds': Genetic Programming trading algorithms, the Marginal Trader Hypothesis and the Hayek Hypothesis.ÊJournal of International Financial Markets, Institutions and Money.

McCauley, J. L., Bassler, K. E., \& Gunaratne, G. H. (2008). Martingales, detrending data, and the efficient market hypothesis.ÊEPhysica A: Statistical Mechanics and its Applications, $\hat{\mathrm{E}} 387(1), 202-216$.

Mobarek, A., \&Fiorante, A. (2014). The prospects of BRIC countries: Testing weakform market efficiency.EResearch in International Business and Finance,30, 217-232.

Mockus, J., \&Raudys, A. (2010). On the Efficient-Market Hypothesis and stock exchange

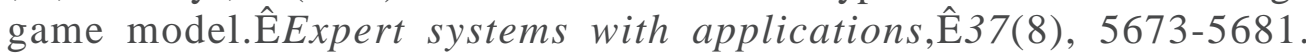

Rizvi, S. A. R., Dewandaru, G., Bacha, O. I., \&Masih, M. (2014). An analysis of stock market efficiency: Developed vs Islamic stock markets using MF-DFA.ÊPhysica A: Statistical Mechanics and its Applications, $\hat{\mathrm{E}} 407,86-99$. Rodriguez, E., Aguilar-Cornejo, M., Femat, R., \& Alvarez-Ramirez, J. (2014). US stock market efficiency over weekly, monthly, quarterly and yearly time scales. $\hat{E} P h y s i c a$ A: Statistical Mechanics and its Applications, $\hat{\mathrm{E}} 413,554-564$. 
Timmermann, A., \& Granger, C. W. (2004). Efficient market hypothesis and forecasting. $\hat{E}$ International Journal of Forecasting, $\hat{\mathrm{E}} 20(1)$, 15-27. Urquhart, A., \& Hudson, R. (2013). Efficient or adaptive markets? Evidence from major stock markets using very long run historic data.ÊInternational Review of Financial Analysis, Ề28, 130-142.

Urquhart, A., \&McGroarty, F. (2014). Calendar effects, market conditions and the Adaptive Market Hypothesis: Evidence from long-run US data.ÊInternational Review of Financial Analysis, $\hat{\mathrm{E}} 35,154-166$.

Verheyden, T., De Moor, L., \& Van den Bossche, F. (2015). Towards a new framework on efficient markets. $\hat{E}$ Research in International Business and Finance, $\hat{\mathrm{E}} 34$, 294-308. 


\section{APPENDIX}

Table 1: Hurst Exponent Test

\begin{tabular}{|c|c|c|c|}
\hline \multicolumn{5}{|c|}{ Rescaled range values for Returns (Logs are to base 2) } \\
\hline Size & RS (avg) & Log (Size) & Log (RS) \\
\hline 275 & 19.800 & 8.1033 & 4.3074 \\
\hline 137 & 16.200 & 7.0980 & 4.0179 \\
\hline 68 & 9.7530 & 6.0875 & 3.2858 \\
\hline 34 & 6.9637 & 5.0875 & 2.7999 \\
\hline 17 & 4.1223 & 4.0875 & 2.0434 \\
\hline 8 & 2.6846 & 3.0000 & 1.4247 \\
\hline Regression results (n=6) & \multicolumn{3}{|c|}{ Coeff std. error } \\
\hline \multicolumn{4}{|c|}{-0.28806} \\
\hline Intercept & 0.58594 & 0.17171 \\
\hline Slope & \multicolumn{3}{c}{} \\
\hline Estimated Hurst exponent $=0.585935$ & 0.029399 \\
\hline
\end{tabular}

Table 2: KPSS test for level Data series

\begin{tabular}{|c|c|c|c|}
\hline KPSS test for $\mathrm{R}$ & & & \\
\hline $\mathrm{T}=276$ & & & \\
\hline Lag truncation & $=5$ & & \\
\hline Test statistic $=3$ & & & \\
\hline & $10 \%$ & $5 \%$ & $1 \%$ \\
\hline Critical values & 0.348 & 0.463 & 0.740 \\
\hline
\end{tabular}

Table 3: KPSS test for 1st Difference Data series

\begin{tabular}{|c|c|c|c|}
\hline \multicolumn{4}{|c|}{ KPSS test for d_Returns } \\
\hline \multicolumn{4}{|c|}{$\mathrm{T}=275$} \\
\hline \multicolumn{4}{|c|}{ Lag truncation parameter $=5$} \\
\hline \multicolumn{4}{|c|}{ Test statistic $=0.876486$} \\
\hline & $10 \%$ & $5 \%$ & $1 \%$ \\
\hline Critical values & 0.348 & 0.463 & 0.740 \\
\hline
\end{tabular}


Table 4: Annual Estimated Hurst Exponent

\begin{tabular}{|c|c|c|}
\hline Year & Calculated Rescaled Range Statistics & Hurst exponent Implies \\
\hline 1992 & 0.661135553 & Persistent \\
\hline 1993 & 0.740443707 & persistent \\
\hline 1994 & 0.682423788 & persistent \\
\hline 1995 & 0.588559579 & persistent \\
\hline 1996 & 0.448757055 & Anti-persistent \\
\hline 1997 & 0.463393275 & Anti-persistent \\
\hline 1998 & 0.476172333 & Anti-persistent \\
\hline 1999 & 0.465405428 & Anti-persistent \\
\hline 2000 & 0.697512853 & persistent \\
\hline 2001 & 0.530043908 & persistent \\
\hline 2002 & 0.892029205 & persistent \\
\hline 2003 & 0.870595164 & persistent \\
\hline 2004 & 0.801437262 & persistent \\
\hline 2005 & 0.796379903 & persistent \\
\hline 2006 & 0.655850447 & persistent \\
\hline 2007 & 0.506408102 & persistent \\
\hline 2008 & 0.685592603 & persistent \\
\hline 2009 & 0.580370667 & persistent \\
\hline 2010 & 0.515317547 & persistent \\
\hline 2011 & 0.455401884 & Anti-persistent \\
\hline 2012 & 0.636522559 & persistent \\
\hline 2013 & 0.65676865 & Anti-persistent \\
\hline 2014 & 0.374515452 & \\
\hline & & \\
\hline
\end{tabular}

\section{Figure 1: Rescaled Range plots for Returns}

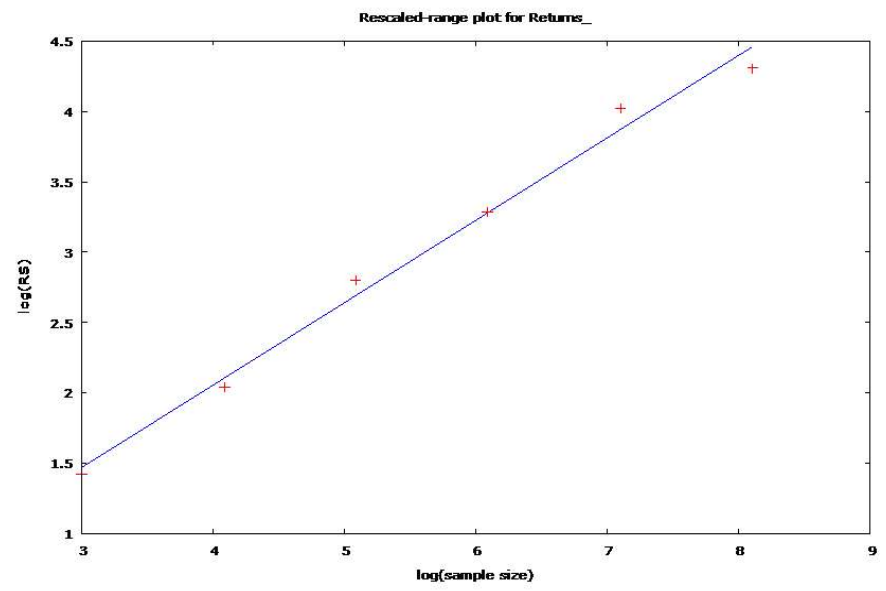


Figure 2: Over all Returns Range

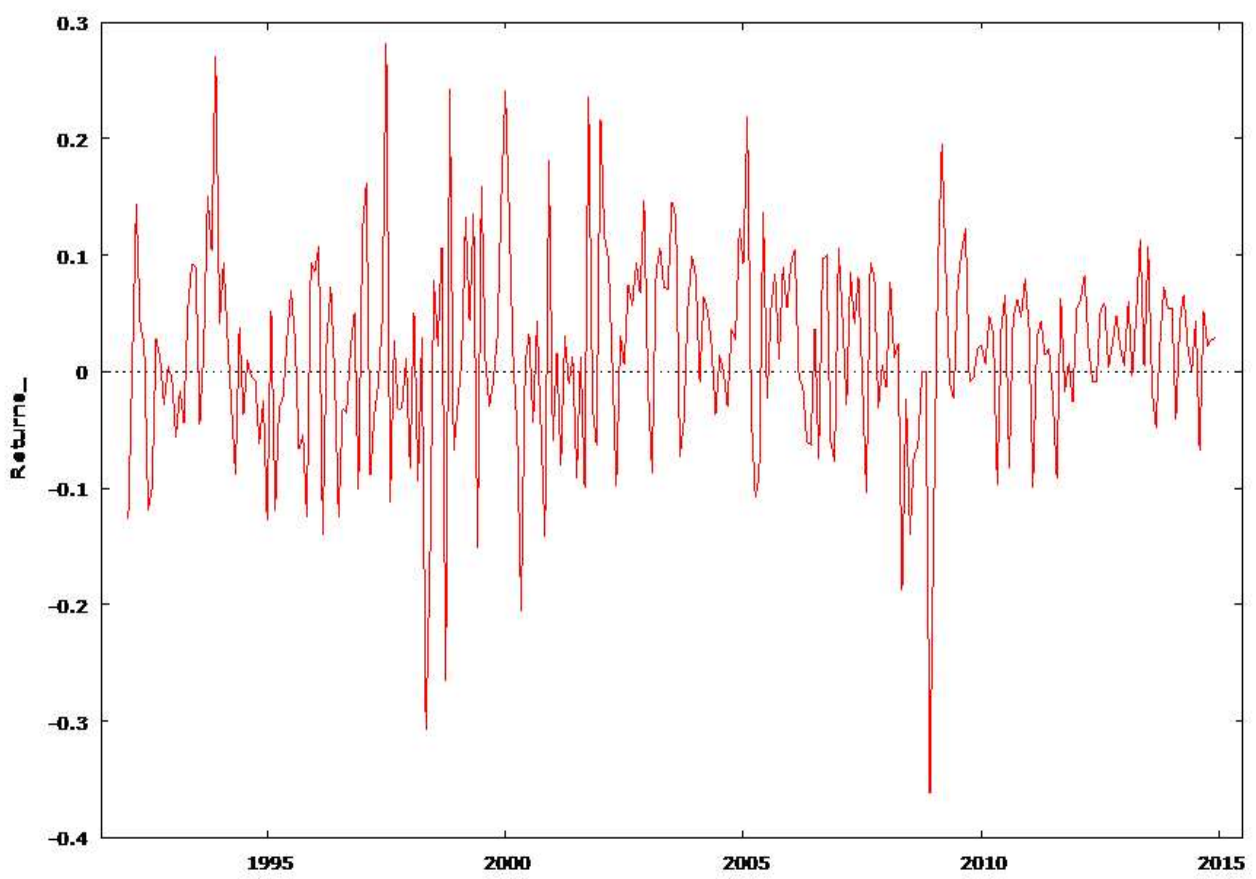

Figure 3: Annual Hurst Range

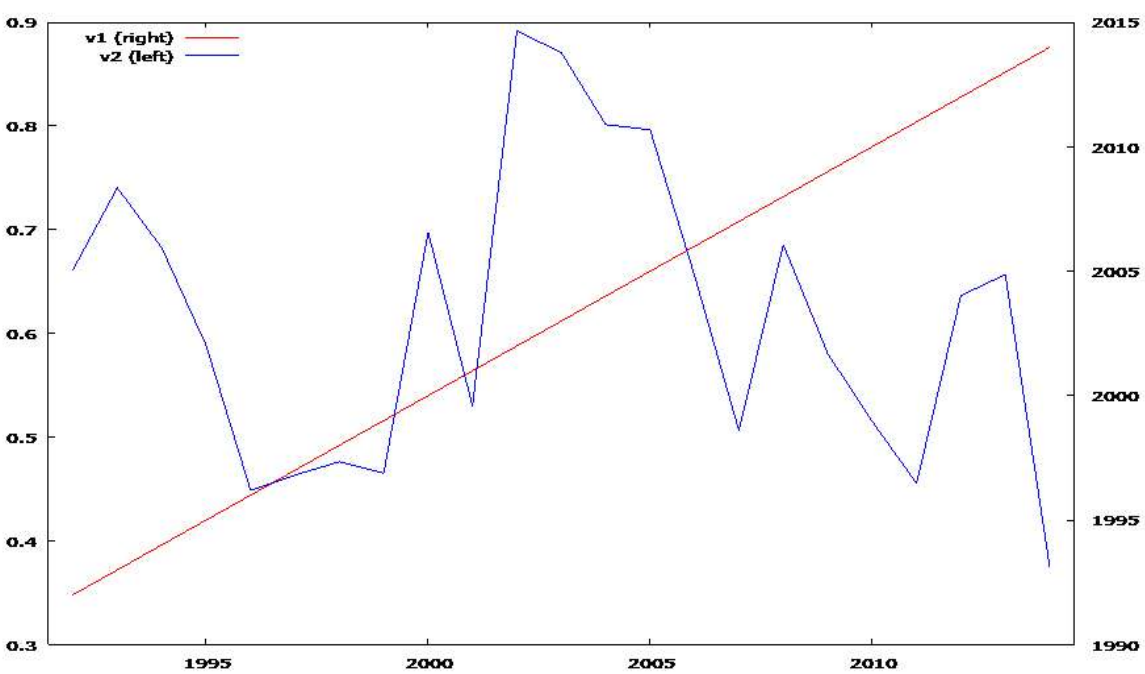

